\title{
Confissões de uma entrevistadora
}

REGINA ZILBERMAN

Universidade Federal do Rio Grande do Sul

\begin{abstract}
In the interviews published by the weekly magazines Manchete and Fatos e Fotos in the mid-1960s, Clarice Lispector had the opportunity to converse with numerous people from the spheres of culture, entertainment and sports. This opportunity allowed her to produce a mapping of celebrities during that period. Lispector's conversations with famous writers, longtime friends, politicians or persons of high society enable her to develop a poetics of the interview and to express her own concept of literature, artistic creation, and reception.
\end{abstract}

Keywords: Clarice Lispector, interview, dialogism, poetics, confessionalism

"Eu me expus nessas entrevistas e consegui assim captar a confiança de meus entrevistados a ponto de eles próprios se exporem. As entrevistas são interessantes porque revelam o inesperado das personalidades entrevistadas. Há muita conversa e não as clássicas perguntas e respostas" (Cambará 88).

Em 19 de dezembro de 1940, foi publicada em Vamos ler! entrevista com Tasso da Silveira, expoente da linhagem espiritualista e católica do Modernismo brasileiro que tinha em Alceu Amoroso Lima um de seus líderes mais respeitados. A entrevistadora era Clarice Lispector; da sua parte, o entrevistado, Tasso da Silveira, dirigia a revista Pan, que, naquele 1940, publicara o conto "Triunfo," com que a repórter e acadêmica da Faculdade de Direito inaugurava sua trajetória na literatura.

A entrevista transcorre em clima amistoso, ao modo de uma conversa entre uma aluna culta e admiradora do entrevistado, e um poeta sábio e profundo, que, por meio de longas exposições, expressa seus projetos literários, as ideias religiosas que professa e a maneira como entende os acontecimentos políticos da 
época. Dentre seus arrazoados, destaca-se a interpretação das causas da derrota da França diante do Terceiro Reich alemão, ocorrida poucos meses antes.

A repórter, já no começo da matéria jornalística, chama a atenção para o tom conversacional da entrevista, ao observar que, ao procurar Tasso da Silveira na redação de Pan, gostava de "puxa[r] uma cadeira e, assim, como quem nada quer, dizia uma palavra, uma simples palavrinha" e, logo, "discutíamos a gênese do mundo, a significação da arte, a explicação do tempo e da eternidade" ("Uma hora com Tasso da Silveira" 18). Por isso, a entrevista, sob a forma inicial de uma narração, é, aparentemente, uma das extensões desses encontros informais, porém densos, que a moça mantém com um de seus editores.

A descontração em que decorre o evento é antecipada pela frase de abertura: "para mim, entrevistar Tasso da Silveira era continuar uma das palestras tão profundas, nas quais eu assistia atenta o poeta revolver os grandes problemas do pensamento" ("Uma hora com Tasso da Silveira" 18). O período inicial do texto também faculta o emergir da primeira pessoa do discurso, personalizando o estatuto da autoria. Mais adiante, a descontração migra para as condições em que se dá o encontro, interrompido, quando "a esposa do poeta" ("Uma hora com Tasso da Silveira" 19) serve um chá aos interlocutores, tornando-se, quase ao final do texto, participante indireta do diálogo, pois é a ela que Tasso da Silveira se refere, conforme relembra a jornalista: "Olha para sua esposa e sorri.-Ela tem ciúmes das personagens, diz que vivo demais com elas" ("Uma hora com Tasso da Silveira" 60). Essa declaração que remete à vida do casal, provoca o comentário da narradora: "D. Noemi protesta e também sorri. É ela a inspiradora e a companheira do escritor, que lhe deve algumas de suas páginas mais suaves e mais felizes" ("Uma hora com Tasso da Silveira" 60), observação que retoma a espontaneidade que Lispector almeja conferir à conversa com o então eminente letrado.

O tom confessional, que se esperaria provir tão somente do entrevistado, marca o discurso da entrevistadora. A primeira pessoa, em evidência desde o começo da matéria, intervém com frequência, não apenas porque são utilizados os pronomes que se referem ao "eu," mas por transmitir impressões particulares experimentadas por quem conduz a fala. Assim, em dada altura, escreve a repórter: "E, perguntei eu, sentindo que chegara a um momento importante da entrevista" ("Uma hora com Tasso da Silveira" 19), como se as declarações de Tasso da Silveira fossem tão relevantes para ela—ou até mais - do que seriam 
para seu leitor. O diálogo converte-se em um aprendizado, que colabora para o amadurecimento da ouvinte.

Outros fatores cooperam para o fortalecimento do tom confessional da entrevista. Em primeiro lugar, o ar de familiaridade já mencionado, acentuado pela alusão à presença da esposa e musa do poeta. Em segundo lugar, a adoção do modo narrativo, expondo as várias etapas do episódio, desde a chegada da moça, até sua despedida, com ocasiões de intensidade maior- como aquele em que ela "sente" ter alcançado um ponto decisivo de sua entrevista - e menor, representada essa pelas reações de D. Noemi. Em outro passo, a narradora interrompe a transcrição das falas de Tasso da Silveira para dar conta de uma reação interior sua: "Sorrio, porque me lembro de que eu também lhe escrevi minha opinião sobre Canto absoluto," sugerindo, no caso, uma superioridade linguística de que se orgulha, já que seu comentário inclui "termos poéticos," como, supostamente, o autor do livro gostaria, apreciador do emprego de "linguagem de surpreendente beleza expressional" por parte dos críticos de sua obra ("Uma hora com Tasso da Silveira" 60).

Fator não menos importante para a construção confessional da matéria, que de certo modo funda a carreira de entrevistadora de Clarice Lispector, é o fechamento do texto, em que ela observa: “'Evidentemente ele é um homem raro, porque, justamente, não é triste. Um dia, num momento de desânimo, pergunteilhe: 'Afinal, 'isso' vale a pena?'. 'Vale a peníssima,' riu ele. Nada melhor explica o poeta e sua obra" ("Uma hora com Tasso da Silveira" 60).

Talvez a frase explique o poeta e sua obra; mas explica principalmente as expectativas da jornalista diante dos indivíduos a quem entrevistava, incumbidos de the transmitir um conhecimento e uma atitude, contribuindo para sua formação interior. $O$ entrevistado vence o desânimo da desalentada moça, ajudando-a a superar a melancolia, amparando-a e, assim, facilitando a passagem pela existência.

A entrevista com Tasso da Silveira talvez permanecesse no limbo das primeiras produções de Clarice Lispector se ela, bem mais tarde, não tivesse retomado a atividade, agora a serviço das revistas Manchete, entre 1968 e 1969, e Fatos \& Fotos, entre 1976 e 1977. Contraposta à experiência futura, pode-se identificar, no produto inaugural, a formulação de uma poética da entrevista, embasada em uma perspectiva confessional. Com esse fundamento, o sujeito que 
entrevista parece tão importante quanto o entrevistado, e dele extravasam formulações que dizem muito de suas ideias e modo de ser.

\section{Diálogos possíveis}

Entre maio de 1968 e outubro de 1969, a revista Manchete, da editora Bloch, manteve a seção Diálogos Possíveis com Clarice Lispector. Manchete nascera em 1952, em época de relativa prosperidade da economia brasileira, beneficiária das vantagens advindas do pós-guerra e, mais adiante, do surto desenvolvimentista liderado pelo presidente Juscelino Kubitschek. A revista aparecera à sombra de O Cruzeiro, fundada por Assis Chateaubriand em $1928 \mathrm{e}$, nos anos 1950, bastante popular graças ao modelo gráfico adotado e à sua política editorial, focada na exploração de episódios que beiravam o escândalo ou o crime.

Manchete competia com $O$ Cruzeiro, quando optava por formato gráfico similar, mas seus propósitos jornalísticos aproximavam-na da francesa Paris Match, da alemã Stern e da norte-americana Life, com a exposição de figuras do jet set brasileiro e do universo pop internacional. Não deixou também de flertar com a literatura elevada, ao incluir, em seu quadro de cronistas e repórteres, nomes como os de Carlos Drummond de Andrade, Paulo Mendes Campos ou Carlos Heitor Cony.

As entrevistas pertenceriam a esse contexto, e Manchete já ostentava uma seção designada Diálogos Impossíveis, título provavelmente levado em conta quando foi preciso nomear o trabalho encomendado a Lispector (Nunes). Por sua vez, a entrevista, enquanto gênero do discurso, já tinha sido alçada a uma categoria literária altamente especializada, principalmente em revistas dirigidas a leitores cultos exigentes (como Playboy, Time, L'Europeo) sendo conduzida por profissionais respeitados. A repórter italiana Oriana Fallaci talvez possa ser nomeada a figura paradigmática para se definir em que constituía a prática da entrevista no novo contexto jornalístico. Primeiramente, por eleger personalidades da mídia, fossem celebridades da política ou do show business; depois, por revelar profundo conhecimento da vida e das ideias do entrevistado, colocando-se em posição paritária ante o sujeito a quem interrogava, independentemente do status desse. No obituário que o londrino The Guardian dedica à jornalista italiana, Liz McGregor e John Hooper reproduzem o modo 
como Fallaci descrevia suas entrevistas, para ela um "coito" ou "uma sedução," o que configura de modo cabal o caráter personalizado e íntimo que assume o diálogo entre arguidor e arguído (Mcgregor and Hooper).

Lispector provavelmente não pensaria assim, nem teria tais expectativas diante das entrevistas que aceitou realizar para Manchete, que, da sua parte, enquanto periódico semanal, assemelhava-se antes ao que são hoje a brasileira Caras ou a espanhola Hola, que a L'Europeo, para o qual trabalhava Oriana Fallaci. Porém, a escritora provavelmente não disporia de muitos paradigmas nacionais, pois, em 1968, a recém-fundada Veja ainda não incluía a seção de entrevistas, impressa em páginas amarelas, celebrizada por acolher personalidades de renome nacional e internacional.

Os Diálogos Possíveis estenderam-se por dezoito meses, perfazendo 59 matérias resultantes de entrevistas, realizadas na maioria das vezes na casa da escritora (Rossi 2006). Dentre os convidados, reconhecem-se nomes originários das artes e da literatura, como os de Bibi Ferreira, Bruno Giorgi, Cassiano Ricardo, Chico Buarque, Fernando Sabino e Jorge Amado, dos quadros políticos do final da década de 1960, como Mário Andreazza, Mário Henrique Simonsen e Negrão de Lima, da cultura de massa, especialmente da televisão, como Glória Magadan e Tarcísio Meira, dos esportes, como Bruno Hermani, João Saldanha, Zagallo, ou da vida mundana, como Tereza Souza Campos, socialite, e Clovis Bornay, carnavalesco.

Parte dessas entrevistas foi reproduzida no livro De corpo inteiro, publicado em 1975, que inclui, além de 27 dos diálogos originais, outras oito conversas (com Alceu Amoroso Lima, Benedito Nunes, Grauben, J. D. Azulay, Nélida Piñon, Ney Braga, Pablo Neruda e João Paulo Reis Velloso) que não procedem de Manchete. Por sua vez, na coletânea de Claire Williams, retornam vinte das entrevistas provenientes de Manchete e que compõem De corpo inteiro, a que se acrescentam os textos dedicados a Augusto Rodrigues, Carybé, Elis Regina, João Saldanha, José Carlos de Oliveira, Mário Cravo, Millôr Fernandes, Nelson Rodrigues, Pedro Bloch e Zagallo. Somadas, as duas obras dão acesso a mais da metade das entrevistas destinadas a Manchete, mas não a todas.

Registre-se, além disso, que a entrevista com Alceu Amoroso Lima, reproduzida nas duas coletâneas, mas não derivada de Manchete, é antecipada em uma das crônicas que a escritora publicou na coluna que assinava no Jornal do Brasil, datada de 9 de fevereiro de 1969 (A descoberta do mundo). Também 
a "Entrevista relâmpago com Pablo Neruda," retomada em De corpo inteiro, pertence ao conjunto de crônicas, o que explica as peculiaridades de sua composição. Porém, em procedimento reverso, as conversas com Tom Jobim, Erico Verissimo, José Carlos (Carlinhos) Oliveira, Marques Rebelo e Pedro Bloch foram recicladas e aproveitadas na seção que lhe competia naquele periódico carioca.

A primeira entrevista reproduzida em De corpo inteiro data de 11 de maio de 1968, sendo seu interlocutor Nelson Rodrigues, que, como dramaturgo, inaugurara a revolução modernista nos palcos brasileiros, em 1943, com a encenação de Vestido de noiva. Era também escritor polêmico, acusado de imoral e censurado por peças teatrais como Álbum de família, proibida em 1946, liberada apenas em 1965 e estreada em 1967. Em 1968, Rodrigues era também autor de crônicas divulgadas em $O$ Globo, do Rio de Janeiro, que consolidaram o entendimento de que se tratava de um intelectual controverso e provocador, ao criticar o comportamento das militâncias de esquerda, fossem conduzidas por estudantes, políticos ou padres.

Exemplar da atitude de Rodrigues é a crônica em que desdenha a "passeata dos cem mil," ocorrida em 26 de junho de 1968, fruto do protesto contra a ditadura militar após a morte do secundarista Edson Luís de Lima Souto, quando a polícia invadiu o restaurante universitário Calabouço para reprimir o movimento estudantil em ebulição. A própria Lispector participara da passeata, mas, antes disso, e provavelmente conhecedora das posições de Rodrigues, abre a série de entrevistas com perguntas dirigidas a ele.

Vale observar que a entrevista com Rodrigues aparece em livro apenas na obra organizada por Williams. O texto não participa da coletânea coordenada ou aprovada pela autora, sendo uma das razões possíveis dessa ausência o fato de, ainda vivo, Rodrigues talvez não ter autorizado sua reprodução; outra causa provável pode ter sido a circunstância de o dramaturgo mostrar-se então, diante da intelectualidade brasileira, ainda uma figura controversa e não suficientemente palatável.

Muitos aspectos distinguem essa entrevista e a que, 28 anos antes, lhe concedera Tasso da Silveira, diferenças que, em parte, poderiam ser atribuídas à passagem do tempo, incidindo em mudanças na sociedade e no amadurecimento da escritora, não mais a jovem de aproximadamente vinte anos, e sim a ficcionista acolhida com respeito pela crítica literária nacional. Cabe igualmente levar em 
conta o tipo de veículo que difundiria o resultado da interlocução entre Rodrigues e Lispector: Vamos ler! era uma revista especializada em cultura, dirigida a um leitor letrado, enquanto que Manchete, destinada a amplo e diversificado público distribuído entre as cidades brasileiras de todo o país, satisfazia-se com generalidades, quando se referia a temas relacionados à arte e a seus representantes mais renomados.

Outros fatores, porém, aproximam os dois textos, a começar com o cenário doméstico e familiar da entrevista: Lispector recebia os entrevistados em casa, tal como Tasso acolheu a repórter em sua residência. A alteração de posições -a proprietária, agora, é a entrevistadora, e não o entrevistado-não modifica a questão principal: as conversas podem ser mais pessoais - e até confessionaisporque o espaço em que ocorrem favorece a propensão à intimidade.

É a conquista da liberdade confessional que faculta a Lispector começar a matéria com o emprego do verbo em primeira pessoa: "avisei a Nelson Rodrigues que desejava uma entrevista diferente" (Williams 28). Nessa frase de abertura, a autora não se constrange tanto em falar de si, quanto em expressar um desejo, dando vazão à vontade manifesta de sua individualidade e à independência intelectual.

Contudo, ao contrário da reportagem com Tasso da Silveira, não se encontram muitos segmentos narrativos ao longo da transcrição da conversa entre Lispector e Rodrigues. Após intensa permuta de perguntas e respostas, a narradora comenta tão somente que, "durante a entrevista toda, ele não sorriu nenhuma vez," a que segue uma sentença, justificando o comentário: "Com a verdade grave não se sorri” (Williams 31). É por um viés distinto que emerge a subjetividade, explorando outra técnica da autora - a de inserir seus sentimentos no contexto da questão formulada. Se a estratégia serve, de uma parte, para estimular uma réplica mais pessoal por parte do entrevistado, de outra, ajuda a iluminar a persona do entrevistador, o qual não se acanha em desvendar suas reações emocionais diante dos acontecimentos que se desenrolam no presente do diálogo.

Assim, após trocar ideias sobre solidão e amizade, o que culmina na declaração, por parte de Rodrigues, de que "o amigo não existe" (Williams 28), conclusão resultante da falta de solidariedade experimentada por ele quando hospitalizado por três meses, Lispector não faz uma pergunta, mas um comentário: "Nelson, como consequência de meu incêndio, passei quase três 
meses no hospital. E recebia visitas até de estranhos. Eu não sou simpática. Mas o que é que eu dei aos outros para que viessem me fazer companhia? Não acredito que não se tenha amigos. É que são raros" (Williams 28). Ainda que não se trate de uma questão, Rodrigues replica: "Ou eu dou muito pouco ou os outros não aceitam o que eu tenho para dar" (Williams 28). A essa declaração segue-se a observação da interlocutora: "Mas você tem sucesso real—e sucesso vem quando se dá alguma coisa aos outros. Você dá" (Williams 29). Estimulado pelo comentário, o dramaturgo narra um episódio, para comprovar suas concepções relativas à amizade e à solidão.

Pode-se concluir que, do ponto de vista estratégico, Lispector é hábil em extrair, da interioridade de Rodrigues, uma experiência particular que talvez o escritor ainda não tivesse compartilhado com outras pessoas ou, ao menos, com outros jornalistas. A tática é eficaz a ponto de levar o interlocutor a definir-se diante da amizade que haveria entre ele e Hélio Pellegrino ou entre ele e Otto Lara Resende, relação que, de certo modo, Rodrigues nega: nenhum deles é seu amigo, "eu é que sou amigo de ambos" (Williams 29), diz; e complementa a afirmação com o relato de incidente ocorrido durante o almoço com Pellegrino, "antes de vir à sua [de Lispector] casa" (Williams 29), em que os dois discutiram.

A estratégia é eficaz, não porque se trate de manobra da autora, mas porque ela não hesita em expor-se, apresentando-se ao leitor como a pessoa que não é simpática e que, mesmo assim, atrai o interesse de estranhos, ao oferecer-lhes algo que não têm e de que carecem. Mais importante que esse comentário, que beira à autoajuda no sentido de que suas obras, de certo modo, socorrem pessoas emocionalmente necessitadas, é o fato de Lispector rememorar o que ocorreu enquanto esteve hospitalizada. $\mathrm{O}$ foco da entrevista é Rodrigues, que lembra sua internação para comprovar a noção de solidão adotada e marca, segundo ele, de sua personalidade e autonomia. A entrevistadora, da sua parte, incorpora episódio similar - e tão pungente quanto o que o dramaturgo vivenciara -, confidenciando ao interlocutor e ao leitor um evento que talvez tivesse se tornado público, mas que, em princípio, não deveria ser assunto da matéria que redigia para Manchete.

Recorrências como essas aparecem em vários textos, colaborando para a composição da personalidade de Lispector para além da sua condição de entrevistadora. O encontro com Teresa Souza Campos, realizado em 14 de dezembro de 1968, reproduzido em De corpo inteiro e excluído de Entrevistas, 
é sintomático da interferência da subjetividade da escritora na condução do diálogo, desde a escolha da interlocutora até a elaboração do texto final.

No contexto dos anos 1960, Campos talvez fosse o avesso de Rodrigues, pois se tratava de uma socialite, personalidade com cadeira cativa na lista das mais elegantes do Rio de Janeiro e pessoa provavelmente afinada com o sistema político então vigente. Mas, como Rodrigues, figurava na imprensa com assiduidade, ainda que seu espaço predileto fosse a coluna social, e não a crônica política ou esportiva. Ícone da moda, provavelmente encarnava a frivolidade da alta burguesia brasileira, em um período em que o país procurava transmitir uma imagem interna e externa de cosmopolitismo, progresso e refinamento.

Ao abrir o texto da matéria para Manchete, a autora declara que foi movida pela curiosidade, ao decidir entrevistar Campos, já que "não simpatizava com ela" (De corpo inteiro 151). Não há evidências de que ela tivesse sido obrigada, pela redação da revista, a procurar a socialite, ainda que Zevi Ghivelder declare à pesquisadora Aparecida Maria Nunes ter sugerido algumas pautas à escritora. Uma delas deveria ter sido dedicada a Pelé, na oportunidade no Rio de Janeiro para disputar uma final de campeonato com seu clube, o Santos. Lispector, conforme relata Ghivelder, pede que Pelé vá a seu apartamento, a fim de poder entrevistá-lo, convite que o atleta não pode aceitar, retido na concentração ao lado dos demais jogadores à espera da partida decisiva (Nunes).

Contudo, com Teresa, aparentemente Lispector faz uma concessão, pois, como narra, deixa à entrevistada a eleição do ponto de encontro: "Country Club, escolheu ela" (De corpo inteiro 151). Mas, combinando por telefone a reunião, não se mostra cortês, ao dizer-lhe que, "apesar de ela ser o primeiro figurino do país, não era sobre isso que eu a entrevistaria" (De corpo inteiro 151). Teresa Souza Campos responde-lhe à altura: "Mas ser o primeiro figurino do país é já alguma coisa!" (De corpo inteiro 151), o que silencia a interlocutora. Para o leitor, porém, explica: "Nada respondi. No entanto, responderia: queiram os céus que Teresa não seja apenas o primeiro figurino do país, senão terei de lhe explicar o que é uma 'pessoa'. E que o Brasil precisa de muito, e não precisa de nada de primeiro figurino" (De corpo inteiro 151).

É uma Lispector mobilizada a quem Campos deverá aguardar, preocupada em armar suas defesas. Porém, seduzida pela voz da interlocutora, que considera "expressiva" e que a "agradava," preocupa-se com a reação que terá: "Iria ela me conquistar para o seu lado? Não, não sou fraca" (De corpo inteiro 152). 
A apresentação dessa entrevista é longa, e inclui ainda um parágrafo incumbido de narrar o encontro das duas mulheres, em que Lispector mais uma vez sublinha a necessidade de se manter atenta, "em guarda," já que Teresa é "diferente," se comparada com as fotografias dela, e "bem mais simpática," o que poderia levar a jornalista a estimá-la, já que "minha tendência é gostar das pessoas" (De corpo inteiro 152). A extensão da abertura contrasta, pois, com o início da entrevista de Rodrigues, concisa e direta. Para desenvolver a nova matéria, a autora recorre a uma forma narrativa próxima ao conto, como já fizera no texto dedicado a Tasso da Silveira, décadas antes e que conserva até o final, já que o fechamento da entrevista expressa os sentimentos de Lispector após a realização da tarefa: "Enfim, contra a minha vontade (estou sorrindo), tomei-me de grande simpatia por Teresa. O seu modo de vida não é culpa dela: ela faz parte de uma engrenagem não evoluída. Tenho certeza de que Campos, em situação diferente, poderia ter grande valor. Ela é o que se chama "une femme d'esprit" (De corpo inteiro 156). Há, pois, ao longo da entrevista, uma história que é aos poucos transmitida ao leitor. Essa narrativa, por sua vez, é protagonizada pela entrevistadora, cuja presença é ainda mais conspícua, se comparada com a que se mostra no texto dedicado a Tasso da Silveira. O que parece interessar à narradora é o próprio ritual de passagem, desde as resistências experimentadas diante da entrevistada, até a aceitação de que é possível reconhecer nela a simpatia que lhe faltava, bem como sua condição humana, que, de certo modo, deplora, pois a considera parte de uma engrenagem anacrônica da máquina social.

Lispector não altera seu parecer, mas modifica a atitude, agora compreensiva e solidária, diante da situação que Campos viveria, com a qual não concorda, pois a afabilidade acontece a contragosto da escritora. Ao narrar essa mudança, aproxima-se bastante das personagens criadas por sua ficção, quando elas transitam de um estado de não saber para o do conhecimento e da consciência, a exemplo de Perto do coração selvagem e de A paixão segundo GH.

Assim, tal como se passa na entrevista de Tasso da Silveira, intensifica-se a presença do eu, agora revelado no presente da ação de escrever, como sugere a afirmação colocada entre parênteses: "(estou sorrindo)." O sujeito, por sua vez, não se percebe menor diante da entrevistada, ainda que, supostamente, essa disponha de atributos que faltam à Lispector mundana, como fama e fortuna. Pelo contrário, assume um papel pedagógico, levando a interlocutora a refletir sobre 
si mesma, na busca das melhores respostas. Com isso, a entrevista, que, se desde a perspectiva da poética adotada flerta com o conto, do ângulo do conteúdo e da condução da troca de falas, aproxima-se do diálogo socrático.

Na Poética, Aristóteles refere-se ao diálogo socrático enquanto uma das modalidades de mimesis ou imitação (246), sugerindo, conforme as notas de Eudoro de Souza, tradutor daquela obra, que o gênero já vinha sendo praticado antes de Platão conferir-lhe a forma com que ficou conhecido (289). De todo modo, foi esse pensador que tornou o diálogo um modelo de produção escrita, caracterizado pela presença de várias personagens que, sob a batuta de Sócrates, discutem problemas filosóficos. Mikhail Bakhtin conferiu particular importância ao diálogo socrático, entendendo como uma das manifestações latentes de polifonia. E, ainda que o exemplo que mais valorize seja o de Luciano de Samósata, não deixa de ter em mente seu cultor mais prestigiado, o ateniense Platão.

Nos diálogos de Platão comparecem vários artifícios argumentativos: o permanente questionamento, dirigido por Sócrates, em princípio representante das teses daquele filósofo, e orientado às pessoas que o procuram; a gradual mudança sofrida por aqueles interlocutores, que, adversários, no início das falas, dos posicionamentos de Sócrates, acabam por se render a seu raciocínio; a aprendizagem resultante das discussões, que repercute sobre a nova visão de mundo ou de ideias por parte do indivíduo ou do grupo de indivíduos com quem Sócrates interage; o inacabamento do texto, que deixa em aberto os temas principais propostos. Esse último recurso linguístico é fundamental na construção do diálogo platônico, porque, ainda que seja educativo, não é suficientemente didático para impor uma concepção única, cerrada e impermeável ao debate. Pelo contrário, ao não oferecer um remate ao modo de uma lição ou de uma moral, permite que os problemas discutidos sejam retomados, reavaliados ou até recusados. Não se mostra, pois, autoritário, porque, se assim fosse, desmentiria o princípio composicional do diálogo, que se desenvolve por meio do intercâmbio de falas a partir de uma lógica discursiva.

A conversa com Campos apresenta esses atributos, divergindo, por este ângulo, da maioria das entrevistas que compõem os Diálogos possíveis presentes em Manchete. Quando formula a primeira pergunta-“Teresa, sua principal ocupação é a moda, não há dúvida. Em segundo lugar o que é que vem?” (De corpo inteiro 152) - a escritora não está agindo de modo diferenciado, se 
comparada essa questão com a que formula a Rodrigues: "Você é da esquerda ou da direita?" (Williams 28). Trata-se, em ambos os casos, de uma provocação, já que Rodrigues, à época, redigia crônicas ferinas contra as esquerdas, mas vinha sendo vítima da censura dos órgãos governamentais desde os anos 1940. Em chave similar, Lispector afirma que, "não há dúvida," Campos ocupa-se em primeiro lugar com a moda.

Assim como Rodrigues, Campos não aceita a proposição de Lispector, contestando que sua "primeira preocupação é existir" (De corpo inteiro 152). Mas, ao reverso do que se passa na entrevista com o dramaturgo, Lispector avança no questionamento: "O que é que você entende por existir?" (De corpo inteiro 152). A nova resposta- “É ser tudo o que eu sou"-não a satisfaz, e Lispector, tal como Sócrates nos diálogos que protagoniza, replica com outra pergunta: "E o que é o que você é?" (De corpo inteiro 152).

Nesse ponto, Campos trava, porque precisa refletir a respeito, o que motiva a intromissão da narradora, que reaparece, apropriando-se da palavra: "Longuíssimo tempo se passa: a pergunta, além de inesperada, é realmente difícil de responder" (De corpo inteiro 152). Percebe que, agora, a interlocutora medita, testemunhando seu "mergulh[o para] dentro de si," a fim de "encontrar a resposta" (De corpo inteiro 152). A nova situação altera não apenas a entrevistada, mas também o posicionamento da entrevistadora, conforme um processo lento de busca do conhecimento de si mesmo e do outro: "Seu olhar [de Campos] tornou-se profundo e, embora de olhos abertos, eles estavam virados para dentro. A partir desse momento a simpatia crescente por Campos aumentou e se estabeleceu" (De corpo inteiro 152).

O episódio não se encerra nessa etapa, pois Campos, em vez de responder, pergunta a Lispector, mas também a si mesma: "O que é que eu sou?—repetiu ela" (De corpo inteiro 152). Retorna a narradora, agora no papel de preceptora, "dando um exemplo," "para facilitar" (De corpo inteiro 152), e usando sua própria situação para motivar a manifestação da interlocutora: "Superficialmente e resumidamente falando, Campos, eu sou mãe de meus filhos e escrevo romances e contos. Superficialmente, repito, é isso o que eu sou. E o problema social que me angustia: eu também sou isso" (De corpo inteiro 152).

Campos, porém, continua imprecisa, ainda que dê uma resposta de amplo espectro-"O que é que eu sou? Nada e tudo"-a que Lispector retruca inquisitorialmente: "Nada em quê?" (De corpo inteiro 152). É só depois de 
Campos esclarecer o sentido de suas palavras - "Nada para muita gente e tudo para o meu filho que é uma evolução minha e uma renovação constante para mim" (De corpo inteiro 153) — que a conversação prossegue. Porque, ao eleger uma resposta, Campos acompanha as escolhas de Lispector, que colocara os filhos em primeiro lugar, antes mesmo de se referir à sua condição de escritora $\mathrm{e}$ ficcionista. Porém, não é ainda o tema da moda e da vida em sociedade que motiva as manifestações de Campos. Afloram questões sobre a vida familiar, a guerra do Vietnã, suas frustrações e alegrias, a fome no mundo, obrigando a expor-se, ainda que o faça com cautela e chame a atenção para a relatividade dos valores. Acompanhando a desenvoltura com que, a partir de dado momento, a entrevistada reage aos assuntos propostos, que reclamam dela um posicionamento, a entrevistadora vê-se no compromisso de lhe solicitar uma avaliação da conversa original que travaram: "Como esta deve ser a primeira vez que dialogam com você sem ser a respeito de moda e beleza, eu queria saber como você se sente tratada por mim como pessoa humana e não apenas uma elegante" (De corpo inteiro 155).

É no contexto de seus valores que Campos avalia o acontecimento, afirmando que foi tratada "elegantemente" (De corpo inteiro 155). É como se, ao final do diálogo, as posições fossem trocadas, ocupando a entrevistada, na última fala, o lugar da entrevistadora, que, no começo, a julgara negativamente, como se faltasse humanidade a ela. O diálogo tornou-se possível graças à permutabilidade dos espaços, avançando naquilo que a fórmula platônica propõe: se há um conhecimento a ser adquirido por intermédio da lógica dos discursos, esse processo precisa envolver todos os usuários da linguagem, sem privilégios de um (ou uma) sobre o outro (ou a outra).

Descendente do gênero que tem em Platão um de seus fundadores, o diálogo praticado por Lispector compreende não apenas o elemento pedagógico da aprendizagem, mas também a reciprocidade que faz com que um sujeito se veja na condição da alteridade, para melhor entendê-lo e apreciá-lo.

\section{Ideias sobre a (própria) criação literária}

Não é apenas quando reproduz os diálogos com os interlocutores que Lispector transpira subjetividade. Em suas perguntas e comentários revela também o modo como concebe a realização de suas obras e, em especial, como experimenta, na 
condição de artista, o processo de criação. Ainda que não se trate de formulações teóricas ou de dissertações argumentativas, ela se apropria de temas que permeiam as reflexões sobre o processo produtivo, bem como sobre a relação com o público.

É nas entrevistas com outros escritores que ela se sente mais confortável para falar de si enquanto criadora, aquela que, além de mãe, elabora romances e contos, como se define diante de Campos. Suas observações decorrem, em parte, da estratégia, já mencionada, de estimular o/a interlocutor/a a exteriorizar suas concepções sobre o fazer artístico; mas, como são informações recorrentes nas entrevistas e reiteradas em crônicas publicadas à época no Jornal do Brasil, podese concluir que são autênticas.

Em conversa com Verissimo, com quem entreteve longa convivência à época em que ambos residiram em Washington, ele diretor do Departamento de Assuntos Culturais da União Pan-Americana, ela esposa de diplomata sediado na capital dos Estados Unidos, Lispector revela que as histórias de seus livros são desenvolvidas sem qualquer plano: "Você planeja de início a história ou ela vai se fazendo aos poucos? Eu, por exemplo, acho que tenho um vago plano inconsciente que vai desabrochando à medida que trabalho" (De corpo inteiro 26).

A falta de planejamento reaparece no diálogo com Rebelo, a quem pergunta se ele " trabalha só quando está inspirado ou tem uma disciplina" (De corpo inteiro 36), prática que ela desconhece. Por isso, confessa ao interlocutor que não reescreve seus textos, podendo, no máximo, acrescentar ou cortar algo. Invertendo os papéis, é Rebelo quem lhe pergunta: "Você escreveu "Uma galinha" assim? Porque me parece fruto de um trabalho enorme," a que ela contesta: "Escrevi 'Uma galinha' entre meia hora ou quarenta minutos, o tempo de bater na máquina" (De corpo inteiro 36).

No diálogo com Sabino, com quem mantinha correspondência assídua desde os anos 1940 (Correspondências), Lispector retoma a questão. Após perguntar se, para ele, "a criação" começa "por uma palavra, uma ideia? É sempre deliberado o seu ato criador? Ou você de repente se vê escrevendo?," afirma, antes de ouvir a resposta do amigo: "Comigo é uma mistura. É claro que tenho o ato deliberador, mas precedido por uma coisa qualquer que não é de modo algum deliberada" (De corpo inteiro 40). Mais adiante, confessa a propósito do deflagrar do processo de produção: "Fernando, você tem medo antes e durante o 
ato criador? Eu tenho: acho-o grande demais para mim. E cada novo livro meu é tão hesitante e assustado como um primeiro livro" (De corpo inteiro 44). Lispector ainda dirige questão similar a Dinah Silveira de Queiroz: após declarar que "o problema da criação artística sempre me fascinou e ainda não perdi a esperança de um dia desmontar esse complicado mecanismo," pergunta à romancista: "Poderia você me dizer qual é a marcha do seu processo de criação?" (De corpo inteiro 61).

No diálogo com os interlocutores Verissimo, Rebelo, Sabino e Silveira de Queiroz, que são também escritores, e prosadores como ela, Lispector expõe as próprias inquietações, inquirindo sobre a origem da criação literária. Para a entrevistadora, é indispensável entender a gênese de uma obra, processo que é interno e vivenciado por todo artista; porém, a natureza enigmática do fenômeno da criação impede sua tradução em palavras. Utiliza a própria experiência como fundamento da indagação, ao chamar atenção para seu procedimento, que é espontâneo, independe de planejamento e pode até ser frenético, como a elaboração de "A galinha," um de seus contos mais conhecidos e prestigiados. Porém, insegura quanto à validade de seu método, o que confessa a seus entrevistados, busca, nos que ouvem suas interrogações, a confirmação de estar agindo de modo apropriado.

Diante dos pares, a escritora não se constrange em apresentar-se como uma artista que, enquanto criadora involuntária, age movida pela intuição, o que não lhe assegura a convicção de que essa é a melhor escolha. A incerteza, exposta em suas perguntas, reitera o caráter peculiar de suas entrevistas, aproximando-a outra vez do modelo socrático, segundo o qual cada interrogação representa uma dúvida que o emissor experimenta e almeja dividir com o destinatário.

Nas entrevistas com escritores, Lispector procede a uma segunda revelação, expondo-se como uma artista irrealizada. A Verissimo, após indagar se ele "se sente realizado como escritor," declara: "Eu, por exemplo, ainda não me sinto, e tenho a impressão de que será assim até eu morrer" (De corpo inteiro 23). Para Pedro Bloch, em entrevista dos tempos de Manchete, reproduzida na coletânea organizada por Williams, a afirmação é quase idêntica: "Eu acho que não consegui me realizar como escritora" (De corpo inteiro 88).

Mesmo assim, não desiste de sua busca e do reconhecimento de que pertence à sua natureza mais íntima ser escritora e encontrar nas palavras a única maneira de se comunicar, como confidencia a Carlinhos de Oliveira, em outra das 
entrevistas oriundas de Manchete, divulgadas em 2007: "Respondo às suas duas perguntas: é tarde demais para mim — escrevo porque não posso ficar muda, não escrevo porque sou profundamente muda e perplexa" (Williams 81).

Lispector desenha a autoimagem de uma artista não muito convicta da qualidade de sua arte, que toma forma sem que adote um desenho prévio. Esse autorretrato resultaria aparentemente de uma concepção idealizada da criação artística, entendida como um gesto incontrolável originário de uma inspiração primária e que não poderia ser regido pela inteligência. Porém, evita mistificar a própria situação, fazendo questão, em mais de uma entrevista, de mostrar-se capaz de elaborar seus textos mesmo em circunstâncias adversas. Assim, na entrevista com Verissimo, lembra em que conjuntura doméstica redigiu A maçã no escuro, romance que, publicado em 1961, constituiu à época sua então mais importante obra:

Erico, sem interromper o assunto, estou me lembrando com saudade de Washington, eu como mulher de diplomata, e você trabalhando na OEA. Você se lembra de como eu fazia ninho na vida e na casa de vocês? Que é que você estava escrevendo naquela ocasião? Eu, por exemplo, estava escrevendo A maçã no escuro. Foi um período muito produtivo, no sentido de trabalho e no sentido de uma amizade que se formou para sempre entre você, Mafalda e eu. (De corpo inteiro 24)

Em entrevista reproduzida em De corpo inteiro, mas que não se originou do conjunto divulgado por Manchete, sustentada com João Paulo de Reis Velloso, Ministro do Planejamento por ocasião da presidência do General Emílio Garrastazu Médici, ela é mais explicita, reproduzindo um cenário que aparece igualmente em muitas de suas crônicas: "Nunca fiquei em transe ao escrever: habituei-me a trabalhar com meus filhos brincando ao meu lado e me fazendo perguntas, eu respondendo, atendendo telefone, atendendo empregada. Lamento muito mas sou um pouco mais saudável do que inventam. Meu mistério é não ter mistério" (De corpo inteiro 209). Por sua vez, embora aparentemente pratique uma escrita em que o espaço geográfico desempenha função pouco representativa - exceção feita a A hora da estrela - Lispector acredita que o lugar onde reside o autor pode colaborar para a produção artística. Assim, 
observa para Jorge Amado, a quem entrevista em Salvador, que, nessa cidade, "eu realmente senti que poderia escrever mais e melhor." Complementa logo a seguir: "Mas o Rio de Janeiro, com o seu ar poluído, não é nada mau, Jorge. Coloca-nos frente a frente com condições adversas e também dessa luta nasce o escritor" (De corpo inteiro 15). Quando conversa com Rebelo, reitera a admiração pelo Rio, bem como o caráter inspirador que tem a cidade: "O Rio é um mundo fascinante, cada bairro tem seus tipos, e você deve ter sentido o Rio nas suas mãos" (De corpo inteiro 37).

Por isso, diante da pergunta que lhe dirige Rebelo, em outra altura em que entrevistadora e entrevistado permutam suas respectivas posições, que indaga dela se "se considera uma escritora brasileira," comenta: "Fiquei pasma com a pergunta, pensei até que ele se referia ao fato de eu ter nascido na Ucrânia e ter chegado ao Brasil com dois meses de idade." Responde então: "Mas é claro: eu penso e sinto em português e só esta língua penosa e terrível me satisfaria" (De corpo inteiro 38-39). Rebelo, em sua interrogação, não se refere à naturalidade da autora ou ao caráter nacional de sua obra (explica ele: "Perguntei-lhe isso, Lispector, porque em geral a literatura brasileira sofre de ausência de densidade, e você é densa"-De corpo inteiro 39); de todo modo, é importante destacar a manifestação convicta de pertença a um mundo, o da língua, aliando-se ao espaço que traduz, eminentemente nacional, em um período em que a recepção crítica à obra de Lispector acusava-a de indiferente à vida e aos problemas brasileiros.

Ainda que os entrevistados de Lispector provenham de distintas categorias profissionais, incluindo-se aí artistas e intelectuais, predominam entre os interlocutores homens e mulheres oriundos do mundo das Letras. Fica subentendido que ela conhece as obras dessas pessoas, ainda que ela não se considere boa leitora, como confia a Rebelo: "Você é um grande leitor? Porque eu, por exemplo, e infelizmente, não sou" (De corpo inteiro 37). Em diálogo com Tom Jobim, declara: "eu não tenho mais paciência de ler ficção" (De corpo inteiro 121).

Também não tem opinião muito favorável sobre o público, de quem espera um desvelo particular, em resposta ao cuidado com que elabora seus textos: "Escrevo com amor e atenção e ternura e dor e pesquisa, e queria de volta, como mínimo, uma atenção e um interesse como o seu [Tom Jobim]" (De corpo inteiro 121). Dessa resposta solícita e amorosa, está excluído o sucesso, que rejeita, 
como expõe a Sabino: "A mim quase que faz mal: encarei o sucesso como uma invasão" (De corpo inteiro 42).

Não foi oportunizado a Lispector testemunhar o próprio êxito, ainda que tenha se referido ao tema na conversa com Sabino. Mas percebeu em que ele incidia, sendo a invasão a que se refere talvez a renúncia à unidade da obra (atualmente bastante fragmentada, e às vezes desfigurada, em livros individuais não previstos pela autora) e à busca permanente pela perfeição, ainda que julgasse não tê-la alcançado. As entrevistas que efetuou, resultantes de uma prática do jornalismo que remonta à sua juventude, corroboram não apenas a coerência de sua atividade intelectual e criadora, mas também o modo particular, pessoal e original com que concebeu e concretizou suas aspirações ao diálogo e à compreensão de si mesma e dos seres humanos com quem conviveu.

Em crônica de 30 de dezembro de 1967, em que narra a entrevista de que foi objeto, publicada no volume 4 do Livro de cabeceira da mulher (Autran, Clarice no escuro; Por que a mulher), a escritora, já então provavelmente gozando de algum sucesso, manifesta sua insatisfação diante do texto final da repórter: "Mas não sei por que, depois que li a entrevista, saí tão vulgar. Não me parece que eu seja vulgar. E nem tenho olhos azuis" (A descoberta 61). Não parece que os entrevistados por Lispector tenham tido impressões negativas dessa natureza, pois Lispector desempenhou com competência sua tarefa. Talvez porque foi tão autêntica ao perguntar, como sempre se mostrou ao longo de sua trajetória literária.

\section{Obras citadas}

Autran, Christina. Clarice no escuro: livro de cabeceira da mulher. Civilização Brasileira, 1967.

-. 'Por que a mulher gosta de apanhar' e outras reportagens dos anos 1960 e 1970. Nova Fronteira, 2007.

Aristóteles. Poética. Traduzido por Eudoro de Souza. Nova Cultural, 1991.

Bakhtin, Mikhail. Problemas da poética de Dostoiévski. Traduzido por Paulo Bezerra, Forense-Universitária, 1981.

Cambará, Isa. "Escritora mágica." Veja, vol. 360, 30 de jul. 1975.

Lispector, Clarice. A descoberta do mundo. Rocco, 1999.

—. Correspondências. Rocco, 2002. 
—. De corpo inteiro. Artenova, 1975.

—. "Uma hora com Tasso da Silveira." Vamos ler!, vol. 5, no. 229, 19 de dez. 1940, pp. 18-19.

Mcgregor, Liz; Hooper, John. "Controversial Italian Journalist Famed for her Interviews and War Reports but Notorious for her Islamaphobia." The Guardian, 16 set. 2006, www.theguardian.com/news/2006/sep/16/ guardianobituaries.italy.

Nóbrega, Livia Pádua, e Goiamérico Felício Carneiro dos Santos. "Clarice Lispector no papel de entrevistadora: a subjetividade em cena." Revista Nexi, no. 2, 2012, revistas.pucsp.br/nexi/article/view/2982/8220.

Nunes, Aparecida Maria. "Entrevistas de Clarice Lispector para a revista Manchete." Intercom, 1996, www.portcom.intercom.org.br/pdfs /6b189d26e42ae986cb86b17ba5114d34.pdf.

Rossi, Vera Helena Saad. Diálogos possíveis com Clarice Lispector: as entrevistas de uma escritora jornalista. 2006, Pontifícia U Católica de São Paulo, Tese de doutoramento.

Williams, Claire, editor. Clarice Lispector: Entrevistas. Rocco, 2007. 